\title{
Applying Geographic Information System (GIS) for Maintenance Strategy Selection
}

\author{
Asma Thamir Ibraheem, Dua'a Abd Al-Razzaq Falih \\ Civil Engineering Department, College of Engineering, Nahrain University, Baghdad, Iraq \\ Email: drasmathamir@yahoo.com
}

Received October 14, 2011; revised November 10, 2011; accepted November 18, 2011

\begin{abstract}
Spatial technologies, such as Geographic Information Systems (GIS), are particularly appropriate for integrating roadway data and enhancing the use and presentation of these data for highway management and operation by using spatial relationships to relate geographic and geometric objects and events. To different degrees, roadway management problems, such as pavement management, involve relations between objects and events located in different spatial positions. Because the data used in the decision-making process have spatial components, the use of spatial technologies emerges as a very appealing alternative. Spatial technologies may enhance the analysis of several transportation-related issues and may improve the quality of the decision-making process. This paper built a GIS based system that provides information for use as a platform on which all aspects of the Pavement Maintenance and Management System (PMMS) process can be built. The resulting system, GPMMS, represents a significant enhancement of all aspects of the PMMS process. A variety of spatially integrated data are important to pavement management decision making. GIS technology is shown to be the most logical way of relating these diverse, but relevant, data. In this paper, 23 sections is selected along the roadways of Nahrain University and all these sections are distresses due to different causes like weathering, ageing, traffic load, and also the bad maintenance, etc. The PSI of these sections in the range between 1 to 4, and most of these sections in the low range (between 1 to 2). That cause of need to future developments including other elements of a road maintenance management system should be considered. Completion of the whole roads database with all the types of surveys recorded i.e. all distresses, construction and maintenance history and so on.
\end{abstract}

Keywords: Highways; GIS; Maintenance; Pavement; PMMS; PMS; Roadway; Spatial Data; Transportation

\section{Introduction}

A comprehensive fully integrated Pavement Maintenance and Management Systems (PMMS), is the key to better reconstruction, restoration and maintenance decisionmaking of pavements. It weaves together information on all pavement inventories, condition and performance databases, and alternative investment options. An operating PMMS provides the road authorities the ability to better plan and manages highway, street, and road pavements. The Pavement Maintenance and Management Systems is a set of tools or methods that can assist decision makers in finding cost effective strategies for providing, evaluating, and maintaining pavements in a serviceable condition. It provides the information necessary to make these decisions. The PMMS consists of two basic components: a comprehensive data base, which contains current and historical information on pavement condition, pavement structure, and traffic. The second component is a set of tools that allows us to determine existing and future pavement conditions, predict financial needs, and identify and prioritize pavement projects [1].

This paper is an essential requirement for project planning and budget allocation. This work will help to reduce the effort needed than in conventional methods, to collect and analyze the data periodically by reducing the repeated works. The present work consists of the analysis of pavement distresses of Nahrain University site. The important aims of this paper are:

1) Flexible pavement deterioration models include deflection and unevenness.

2) Present serviceability rating models representing structural condition and also functional condition model.

3) The performance and life of the overlay has been assured on the basis of acceptable limits for deflection.

\section{Present Serviceability Index (PSI)}

The Present Serviceability Index (PSI) is based on the original AASHO Road Test PSR. Basically, the PSR is a ride quality rating that required a panel of observers to actually ride in an automobile over the pavement in 
question. Since this type of rating is not practical for large-scale pavement networks, a transition to a nonpanel based system is needed [2].

To transition from a PSR serviceability measure (panel developed) to a PSI serviceability measure (no panel required), a panel of raters during 1958 to 1960 rated various roads in the states of Illinois, Minnesota, and Indiana for PSR. This information is then correlated to various pavement measurements (such as slope variance (profile), cracking, etc.) to develop PSI equations. Further, the raters are asked to provide an opinion as to whether a specific pavement assessed for PSR was "acceptable" or "unacceptable" as a primary highway as shown in Figure 1. Thus, although PSI is based on the same 5-point rating system as PSR it goes beyond a simple assessment of ride quality. About one-half of the panel of raters found a PSR of 3.0 acceptable and a PSR of 2.5 unacceptable. Such information is useful in selecting terminal or (failure) serviceability (PSI) design input for empirical structural design equations. It is interesting to note that the original AASHO Road Test rater opinions are based on car ride dynamics; it is unclear whether such levels are acceptable for trucks [3].

\section{Pavement Maintenance Treatments}

The selection of the right maintenance strategy at the right time is of utmost importance for an effective management of highway pavements. The appropriate maintenance strategy will be influenced by the type, severity, and extent of the pavement surface distresses and the structural and roughness condition of the pavement. Choosing the right treatment also depends on the extent or frequency that the distress occurs. Some of the treatments may be most applicable when very little distress is present. Pavement Decision Matrix shown as Table 1, where the extent of the distress is described as a "Trace" or "Occasional", it may also be regarded as occurring in localized areas only and affecting less than $30 \%$ of the pavement surface. If the extent is described as "Frequent", "Extensive", or "Complete", the distress affects more than $30 \%$ of the pavement surface and occurs more or less evenly throughout the section. Application of the extent rating is generally the same for Flexible and Rigid pavements. However, the Rigid Pavement Decision Matrix shown as Table 2, points out some exceptions; i.e., in the rating of Transverse Cracks and Surface Distress [4].

\section{The Application of GIS in Pavement Maintenance}

Since geographical information systems with their spatial analysis capabilities, match the geographical nature of the road networks, they are considered to be the most appropriate tools to enhance pavement management operations, with features such as graphical display of pavement condition.

Nowadays, as GIS is increasingly used in public authorities, there is a growing trend toward integrating PMS data into the GIS. With the technological advances in computer hardware and software, this integration is becoming more realistic. Advantages of such integration include flexible database editing and the ability to visually display the results of database queries, statistics and

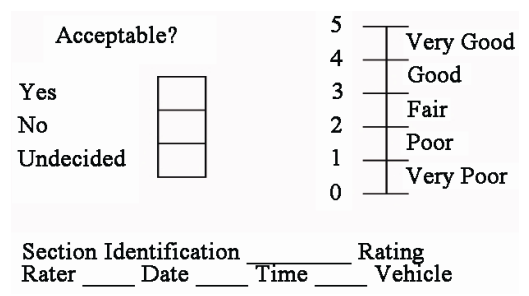

Figure 1. Individual present serviceability rating form [3].

Table 1. Flexible pavement maintenance decision matrix ${ }^{1}[4]$.

\begin{tabular}{|c|c|c|c|c|c|c|}
\hline \multirow{2}{*}{ Flexible Pavement Distresses } & \multicolumn{2}{|c|}{ Low } & \multicolumn{2}{|c|}{ Moderate } & \multicolumn{2}{|c|}{ High } \\
\hline & Occasional & Frequent & Occasional & Occasional & Frequent & Occasional \\
\hline Alligator Cracking ${ }^{2}$ & 3,1 & 3,6 & $6,3,11,4$ & 6,5 & $13,6,11$ & 15,13 \\
\hline Edge Cracking & 1,2 & 2,1 & 2,13 & 2,13 & 13 & 13 \\
\hline Longitudinal Cracking & 2,1 & $2,6,1$ & 2,6 & 2,6 & $13,2,6$ & $6,2,13$ \\
\hline Random/Block Cracking & 2,1 & 2,3 & 2,6 & 2,6 & $6,11,12$ & $12,6,14$ \\
\hline Raveling/Weathering & $3,1,6$ & $3,6,5$ & 6,7 & 6,7 & $6,11,5$ & $6,12,11$ \\
\hline Distortion & $1,8,13$ & $13,1,8$ & $8,13,6,2$ & $8,13,6,2$ & $8,11,6,13$ & $8,14,13$ \\
\hline Rutting & 1 & 1 & $8+6$ & $8+6$ & $8+6,12$ & $8,14,13$ \\
\hline Excess Asphalt & 1 & 1,6 & $6,1,8$ & 6,8 & $8+6$ & $8+6$ or $12^{3}$ \\
\hline Transverse Cracking & 2,1 & 2 & 2,6 & 2,6 & 2,6 & $2,6,13$ \\
\hline
\end{tabular}

Pavement Treatments: 1) Do Nothing; 2) Crack Seal/Fill; 3) Fog Seal; 4) Scrub Seal (Broom Seal); 5) Slurry Seal; 6) Chip Seal/Armor Coat; 7) Micro Surfacing; 8) Mill; 9) Cold-In-Place Recycle; 10) Hot-In-Place Recycle; 11) Thin Cold Mix Overlay; 12)Thin Hot Mix Overlay; 13) Patching; 14) Thick Overlay; 15) Total Reconstruction. ' Based on recommendations of the eight District Maintenance Superintendents and Materials \& Research Division. Treatment are listed based on the frequency with which they were selected. Only treatments shown are those which were selected by more than two of the group. Other possible treatment are listed on the pages showing the distresses. ${ }^{2}$ Effectiveness of treatments other than 13,14 \& 15 will be minimal and short-lived. ${ }^{3}$ Pavement Extension Program (PEP) projects are typically 2 inches thick and are considered the maximum thickness of this treatment. 
Table 2. Rigid pavement maintenance decision matrix [4].

\begin{tabular}{|c|c|c|c|c|c|c|}
\hline \multirow{2}{*}{ Rigid Pavement Distresses } & \multicolumn{2}{|c|}{ Low } & \multicolumn{2}{|c|}{ Moderate } & \multicolumn{2}{|c|}{ High } \\
\hline & Occasional & Frequent & Occasional & Frequent & Occasional & Frequent \\
\hline Joint Distress & 1,2 & 1,2 & 2,3 & 2,3 & 3,4 & 3,4 \\
\hline Faulting & 1 & 1 & 1 & $6,4,1$ & 6,4 & 6,4 \\
\hline Transverse Cracks & 1,2 & 1,2 & $\mathrm{NR}^{*}$ & $\mathrm{NR}^{*}$ & $2,8,4$ & $2,4,8$ \\
\hline Pattern Cracking & 1 & 1 & 1 & 1 & 1,4 & 1,4 \\
\hline Surface Distress $^{* *}$ & & & & $3,8,4$ & & \\
\hline Slab Cracking & 2 & 2,4 & 2,7 & $2,7,4$ & 3,9 & 3,9 \\
\hline
\end{tabular}

*Not Rated; ${ }^{* *}$ Measured as square feet/panel; Pavement Treatments: 1) Do Nothing; 2) Crack \& Joint Seal/Fill; 3) Partial/Full Depth Slab/Joint Repair; 4) Thin Hot Mix Overlay ( $1 \frac{1}{2} "$ ); 5) Mudjacking; 6) Diamond Grinding (may include dowel bar retrofit); 7) Cross Stitching; 8) Slab Replacement; 9) Thick Hot Mix Overlay.

charting, pavement management analyses on a map of the highway network, view network conditions through dynamic color-coding of highway sections, and access sectional data through the graphical map interface.

Spatial technologies, such as Geographic Information Systems (GIS), are particularly appropriate for integrating highway data and enhancing the use and presentation of these data for highway management and operation by using spatial relationships to relate geographic and geometric objects and events. Two different degrees, highway management problems, such as pavement management, involve relations between objects and events located in different spatial positions. Road networks extend over a wide area and interact with various land elements, including rivers, mountains, buildings, and other roads. Because the data used in the decision-making process have spatial components, the use of spatial technologies emerges as a very appealing alternative. Spatial technologies may enhance the analysis of several transportation-related issues and may improve the quality of the decision-making process [5].

There is no doubt that the quality and efficiency of roads affect the quality of life, the health of the social system and the continuity of economic and business activities. Deterioration and catastrophic failure of these roads may occur because of aging, overuse, misuse and/ or mismanagement. Timely pavement maintenance programs can reduce the rate of deterioration, prolong life of pavements, reduce vehicle operating cost and ensure safety to road users. Generally, pavement treatment strategies can be ranged from sealing, routine patching, overlaying to reconstruction as a last option.

GIS uses a coordinate system to define the location of each feature of the pavement network. It is a strong visual aid for the representation of both present and future pavement conditions. Arcview was adopted as the GIS developmental tool to design system architecture, integrate data formats, import databases, and code all models in sequence. Combining road maps with all relative in- formation in this system, not only pavement engineers can monitor pavement condition at anytime, but also maintenance budgets can be estimated. PMMS-GIS provide authorities as a reference for advanced exploration and can certainly enhance the efficiency and quality of pavement maintenance by means of advanced computations.

A Pavement Maintenance Management System should not be confused with a Pavement Management System (PMS). A PMMS is a part of a PMS program, i.e. they overlay rather than replace one to another. Figure 2 shows PMMS versus PMS and the concept of the overlay between them [6].

\section{Case Study}

Nahrain university has a great importance because it one of the biggest universities in the country (Iraq), and there are many people come to it from different towns for studying and education, consequently, it attracts heavy traffic volumes as well as different types of transportation means. Thus a complete data base was developed for the University by using ArcView (Ver 3.3), and achieved by two steps: first making a data base, and second by integrating the PMS with GIS as follows.

\subsection{Data Base}

The ArcView is a full-featured Geographic Information System (GIS) software for visualizing, managing, creating, and analyzing geographic data. Figure $\mathbf{3}$ shows some of the districts of Nahrain University, which was chosen from Google earth and worked on it to make an initial data base for this university.

After that, click on the View pull down menu and then choose New Theme, shown in Figure 4.

The New Theme dialog box will appears, choose one of three choices (Point, Line, and Polygon) for example line, as shown in Figure 5.

Saving dialog box will appear, as shown in Figure 6. 


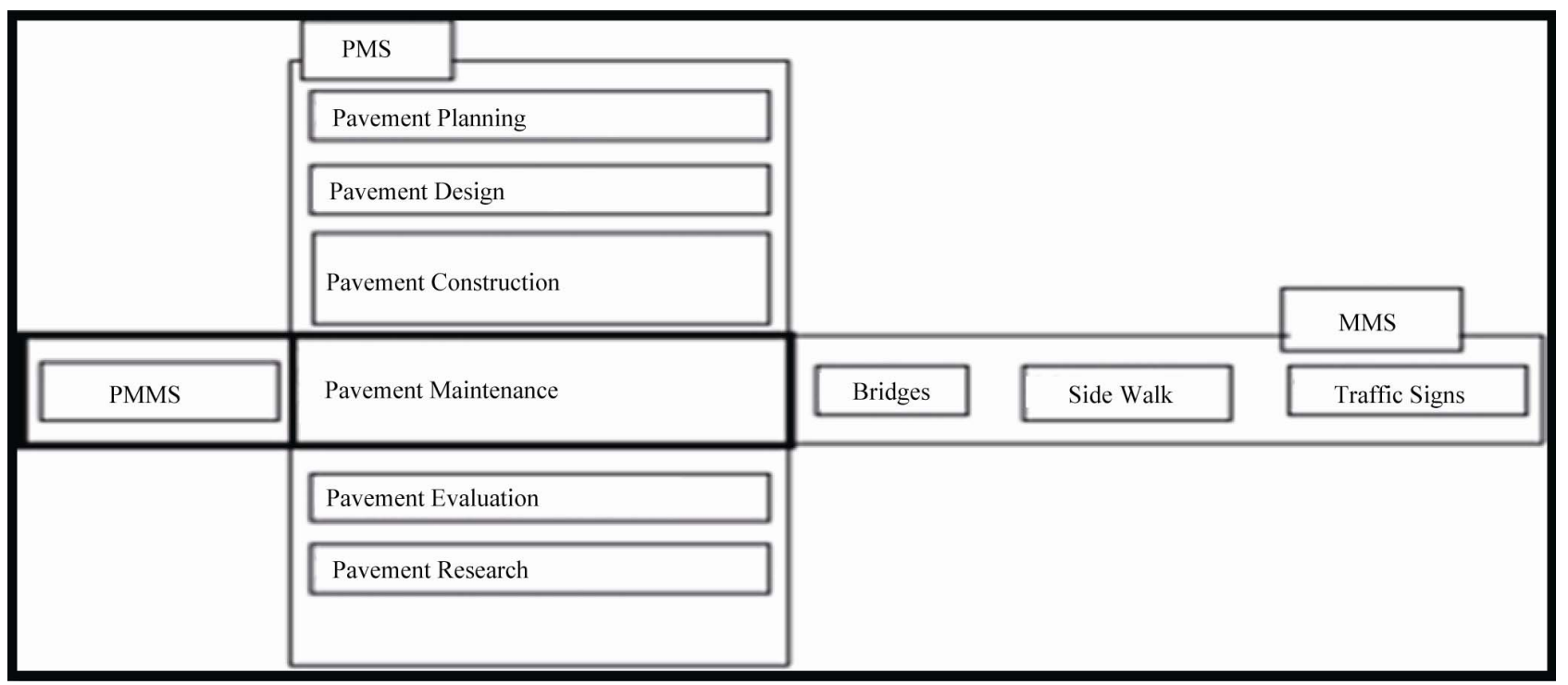

Figure 2. Pavement Maintenance Management Systems (PMMS) versus Pavement Management System (PMS).

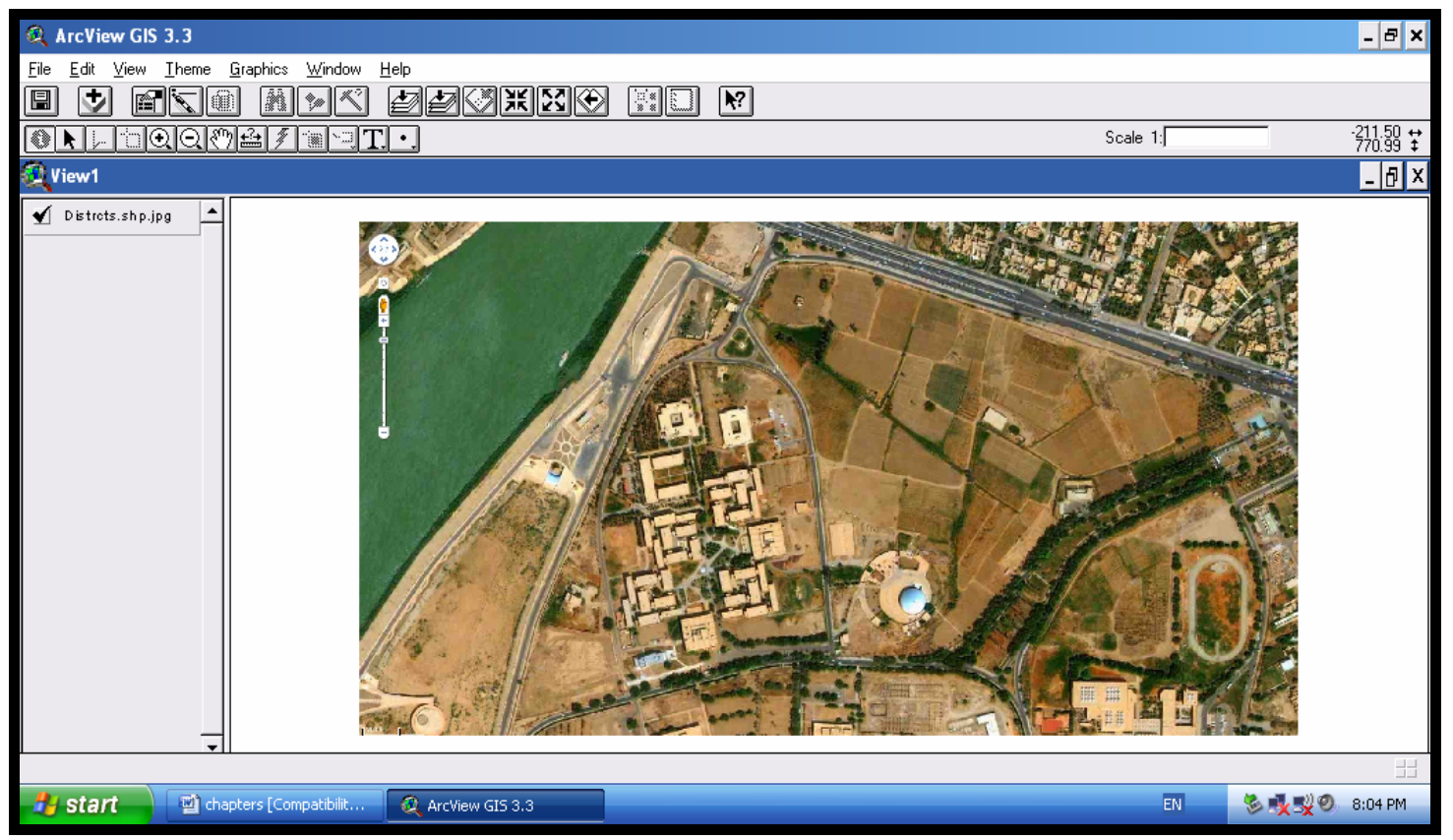

Figure 3. The districts of Nahrain, Google Earth, last seen in 1/3/2011.

After saving the new theme we can now to draw a new theme like the main road as shown in Figure 7.

By this way we make the following themes:

1) Main road use theme: in this theme, it will notice all university main roads as shown in Figure 8.

2) Local road theme: this theme contents all the local roads of university as shown in Figure 9.

3) Park theme: this theme contents all the parks of university as shown in Figure 10.

4) Passing road theme: this theme contents the passing roads of university as shown in Figure 11.

By selecting all the themes, parks, major roads, local roads and passing roads, the map will be as shown in Figure 12.

\subsection{PMS/GIS Integration}

Since geographical information systems with their spatial analysis capabilities, match the geographical nature of the road networks, they are considered to be the most appropriate tools to enhance pavement management operations, with features such as graphical display of pavement condition [7].

Nowadays, as GIS is increasingly used in public au- 


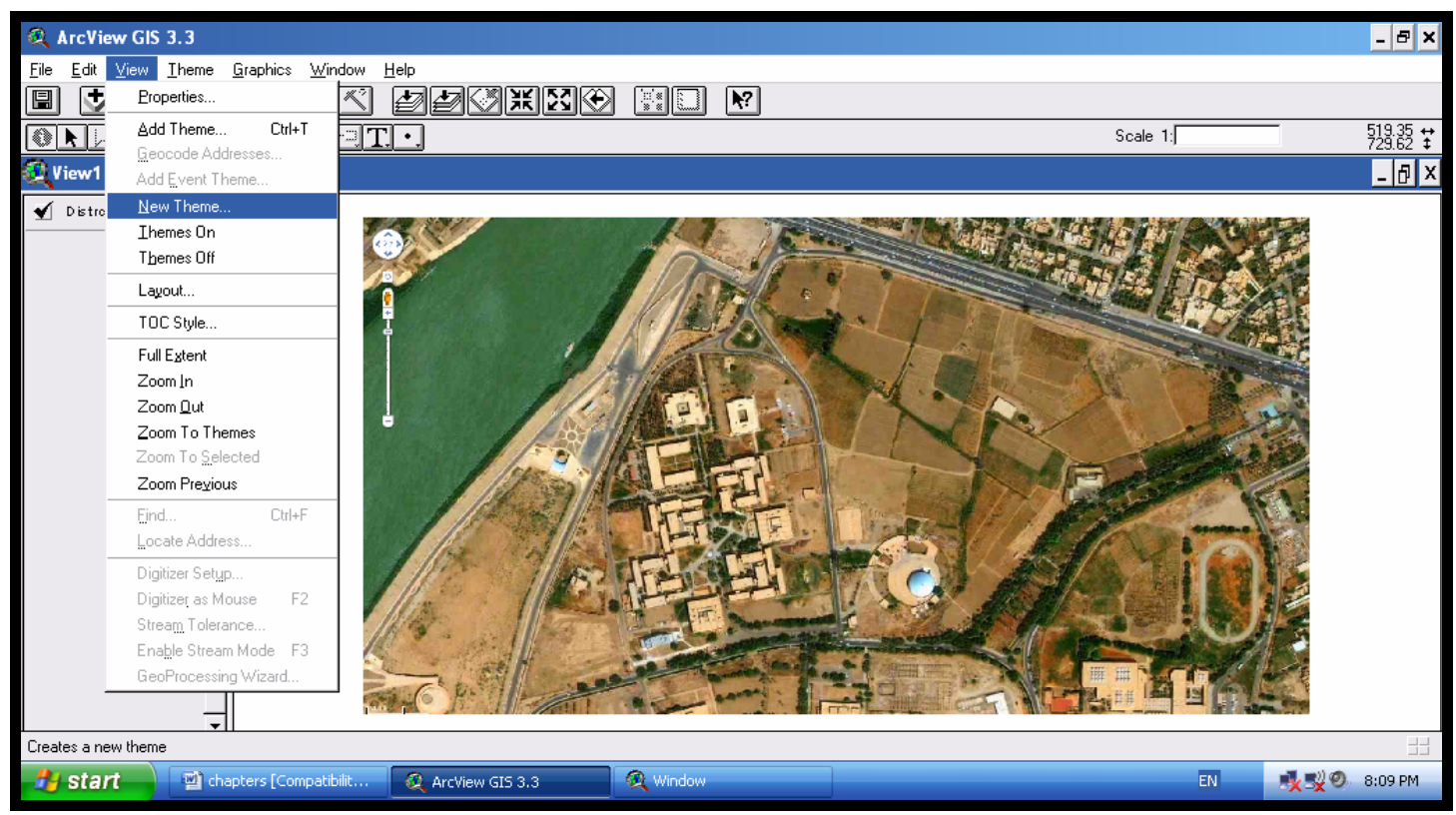

Figure 4. The new theme.

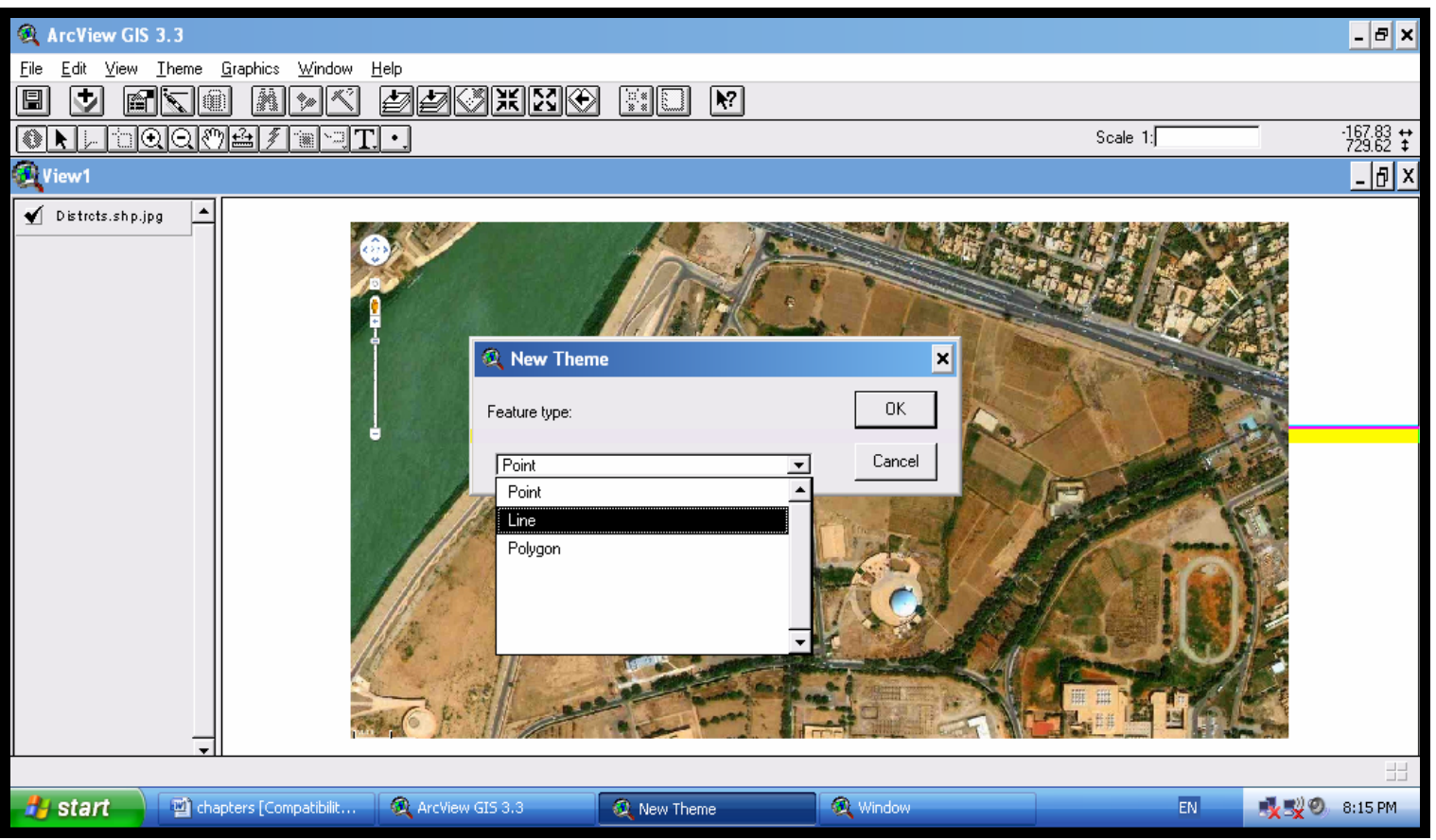

Figure 5. The new theme dialog box.

thorities, there is a growing trend toward integrating PMS data into the GIS. With the technological advances in computer hardware and software, this integration is becoming more realistic. Advantages of such integration include flexible database editing and the ability to visually display the results of database queries, statistics and charting, pavement management analyses on a map of the highway network, view network conditions through dynamic colour-coding of highway sections, and access sectional data through the graphical map interface $[8,9]$.

The pavements of the university under study have the following current threats:

- Increase rate of deterioration (pavements deteriorate fast).

- Overloading of vehicles (no commitment with the legal loading).

- Rapid traffic growth (High increase of vehicle ownership). 


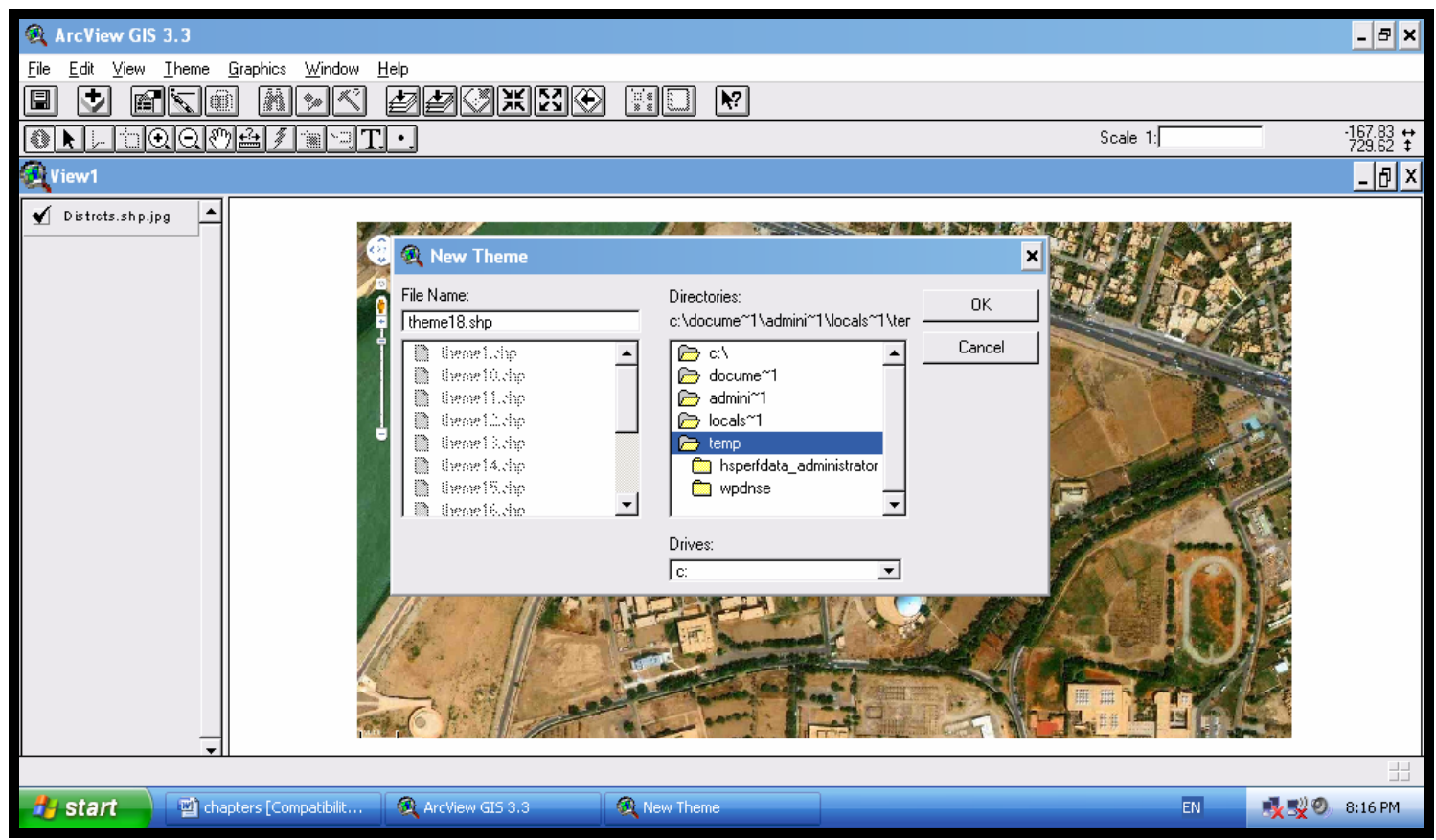

Figure 6. Saving dialog box.

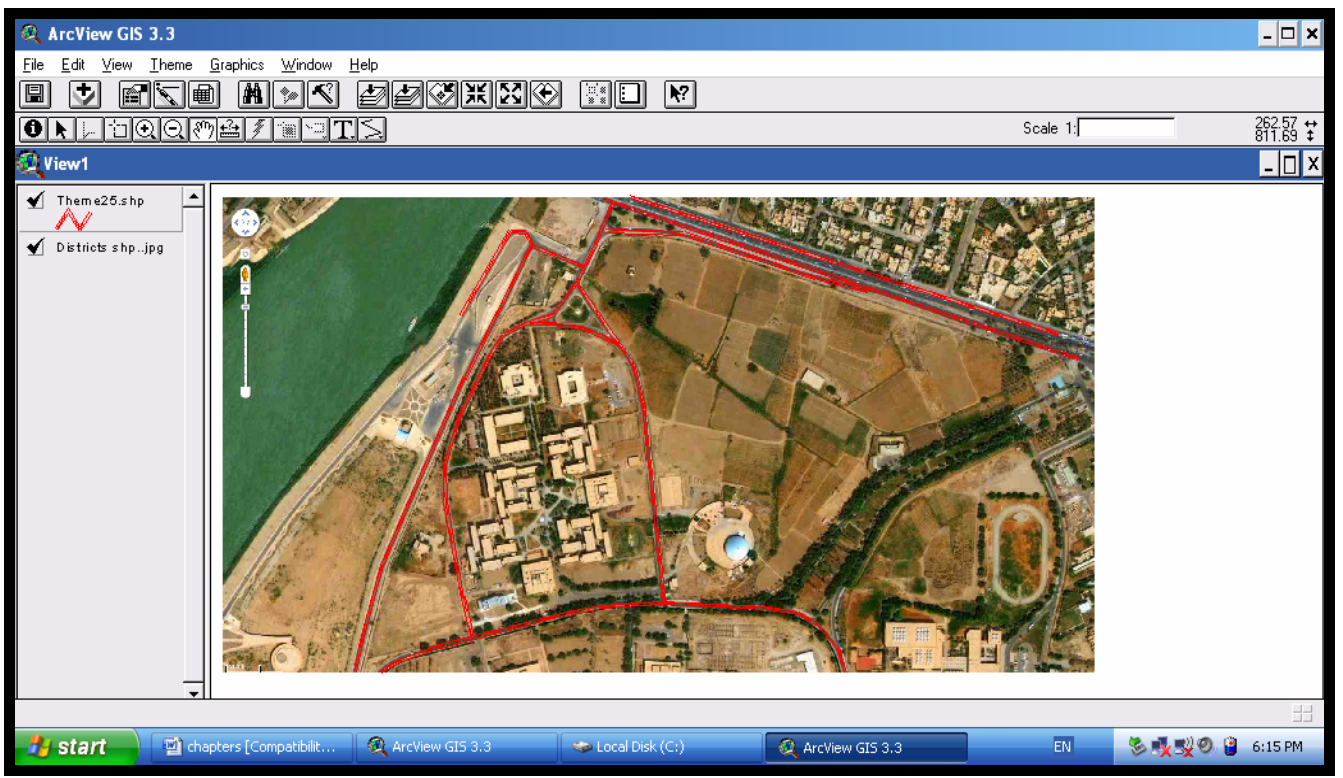

Figure 7. Draw the main road.

- Poor maintenance (improper materials, wrong implementation, etc.).

- Improper design and implementation.

- Insufficient information for decision-making.

- Inefficient current traditional management system. The traditional maintenance system that is currently in use reveals that:

- There is a lack of documentation.

- There is no use of database programs in storing and processing the system data.
- The system is not flexible enough to adjust work plans and schedules to reflect changing conditions.

- The system is poor to assist in making decisions. From the above mentioned points, there is a strong need for a comprehensive PMMS in Iraq that involves:

- Databases: facilitate the physical data of the system to be managed and allow data storing, retrieving, displaying, updating and getting queries.

- GIS capabilities: allow representing the inventory data and reporting in a geographic format. 


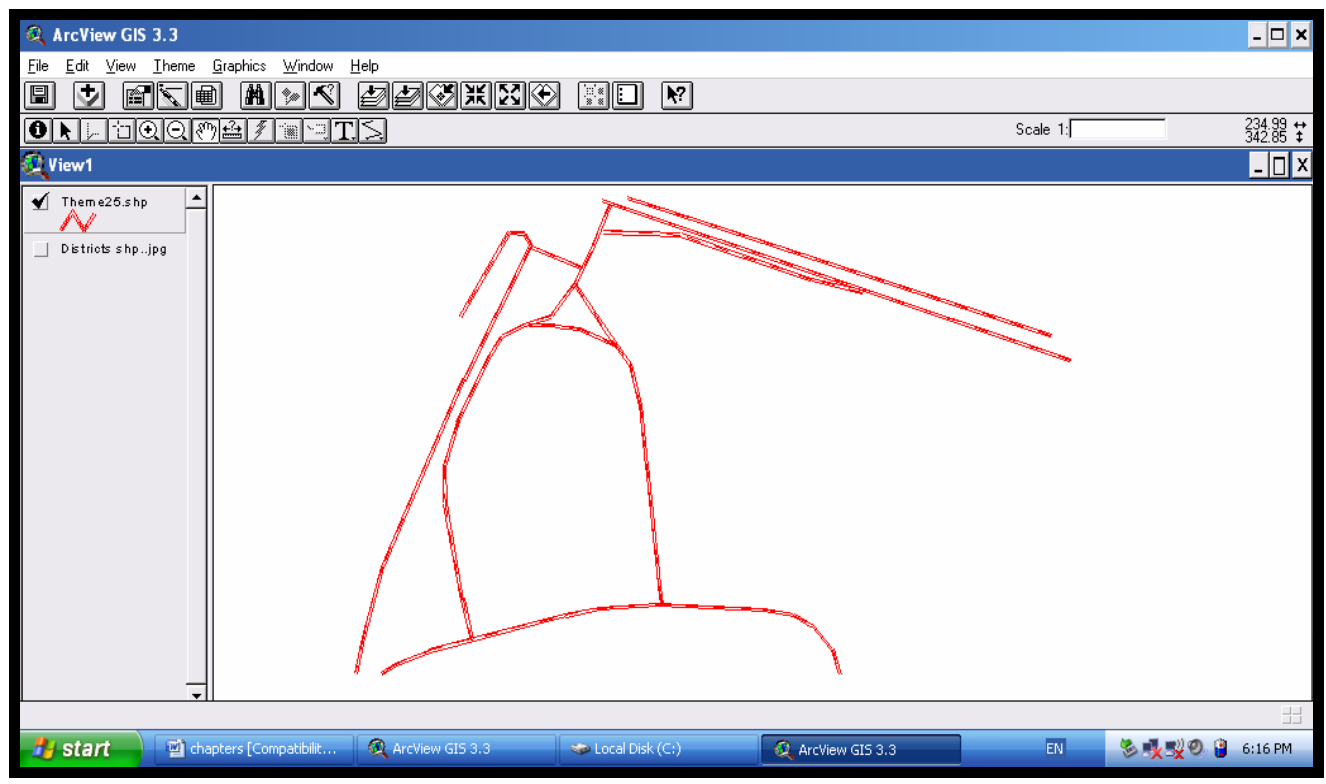

Figure 8. Main road use theme.

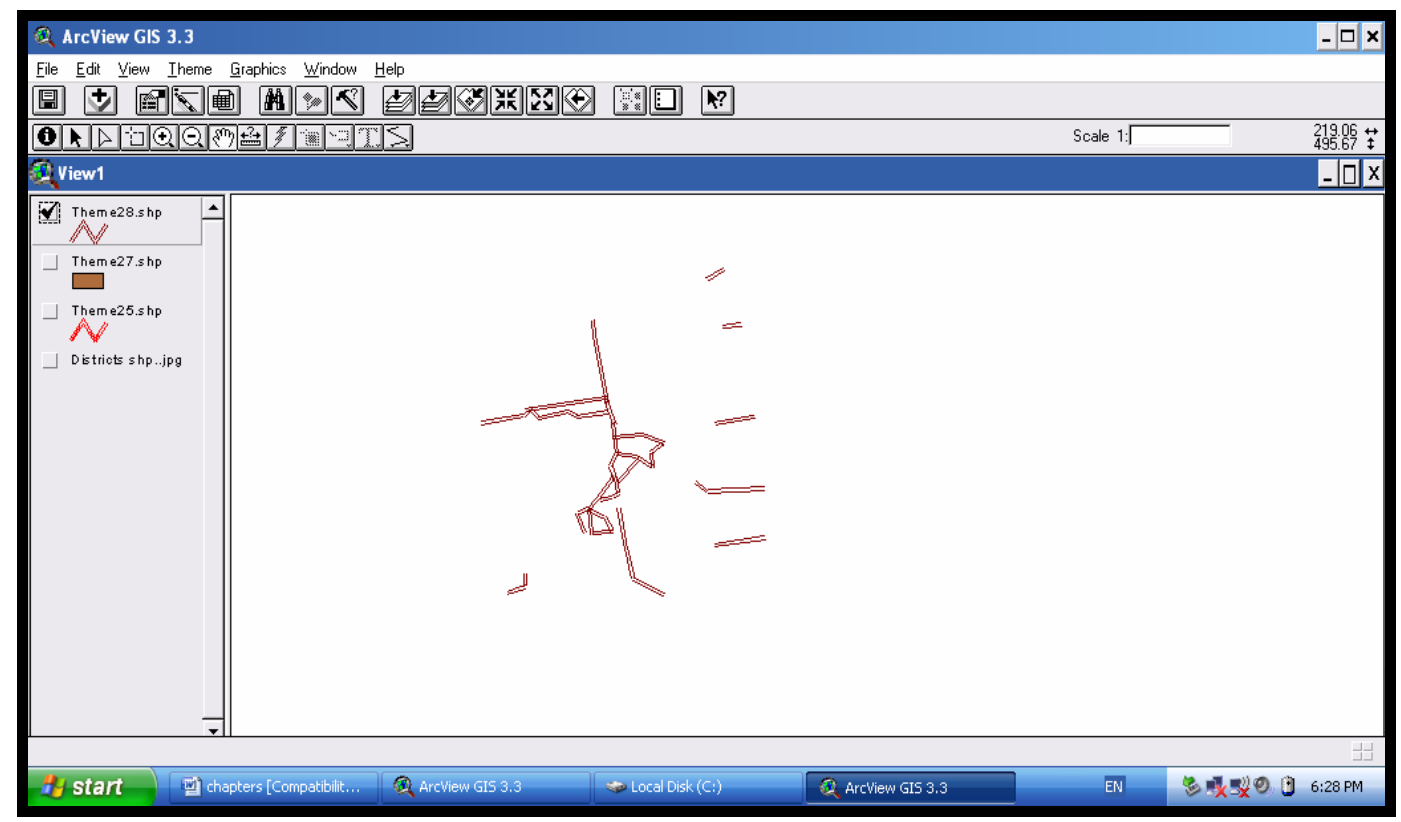

Figure 9. Local road theme.

- Evaluation system: assists in making timely cost effective decisions related to the maintenance and rehabilitation of pavements.

- Modeling system: provides information about maintenance needs, costs, priorities, etc.

To analyze Nahrain University PMMS, a detailed visual inspection survey was conducted to a case study sections illustrated in Figures $\mathbf{1 3}$ and $\mathbf{1 4}$ and selected these sections shown as points.

The inspection data is first analyzed to determine the PSI value and suggested many treatments for each sec- tion of the case study zone. Information about any pavement section can be easily obtained by clicking this section on the pavement network map, as shown the Figures 15 and 16.

The details of these sections are shown in Table 3 below, and the figures of these sections are shown in Table 3 below.

\section{Conclusions}

In this work, the following conclusions can be drawn:

1) The spatial nature of transportation data makes GIS 


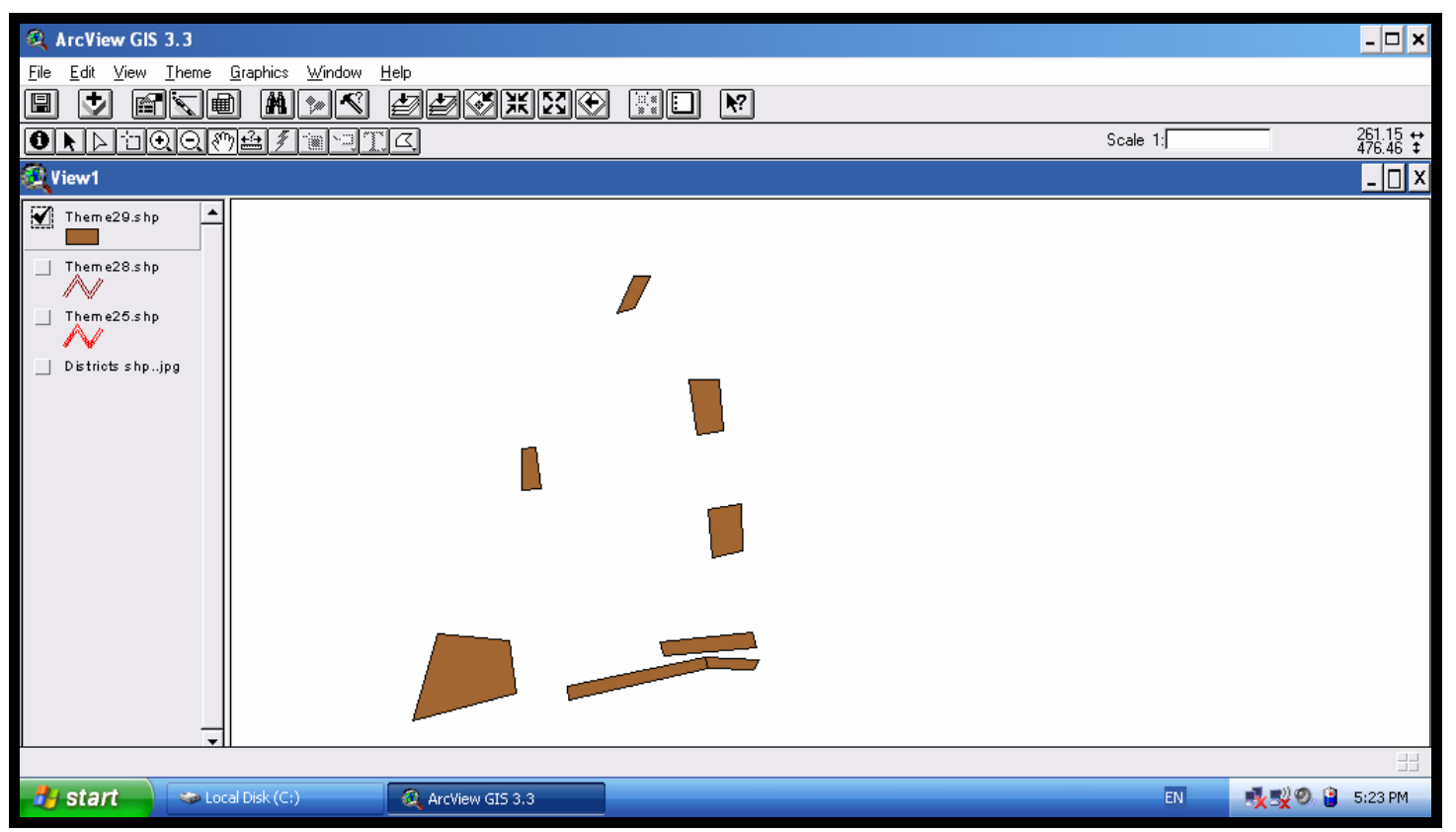

Figure 10. Park theme.

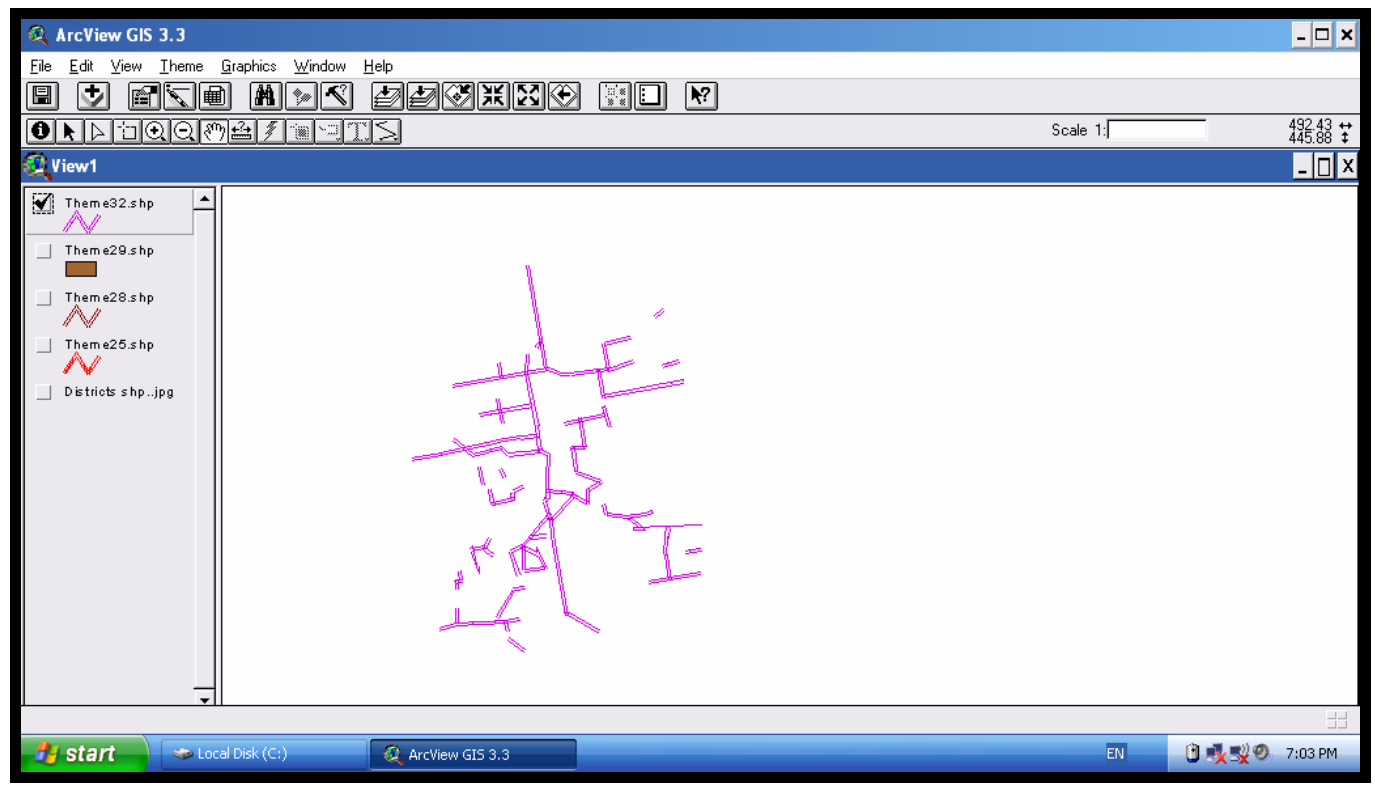

Figure 11. Passing roads theme.

a logical choice on which to base systems such as PMS. GIS has proved to be an effective tool for integrating, managing, storing, displaying, mapping, querying, and spatially analyzing transportation data.

2) PMS should be considered a tool for decision making, not a decision maker in and of itself. These systems are not intended to replace engineering expertise and judgment, but rather to help in making cost-effective decisions. The system should be flexible enough to incorporate user input in the decision making process.

3) There are many variables that influence the selec- tion of the right treatment. After the treatment is selected, there are still many choices as to the proper procedures and materials to use.

4) In this work, 23 sections was selected from the roads of Nahrain University and all these sections are distresses due to different causes like weathering, ageing, traffic load, and also the bad maintenance, etc.

5) Future developments including other elements of a road maintenance management system should be considered. Completion of the whole roads database with all the types of surveys recorded i.e. all distresses, construction 


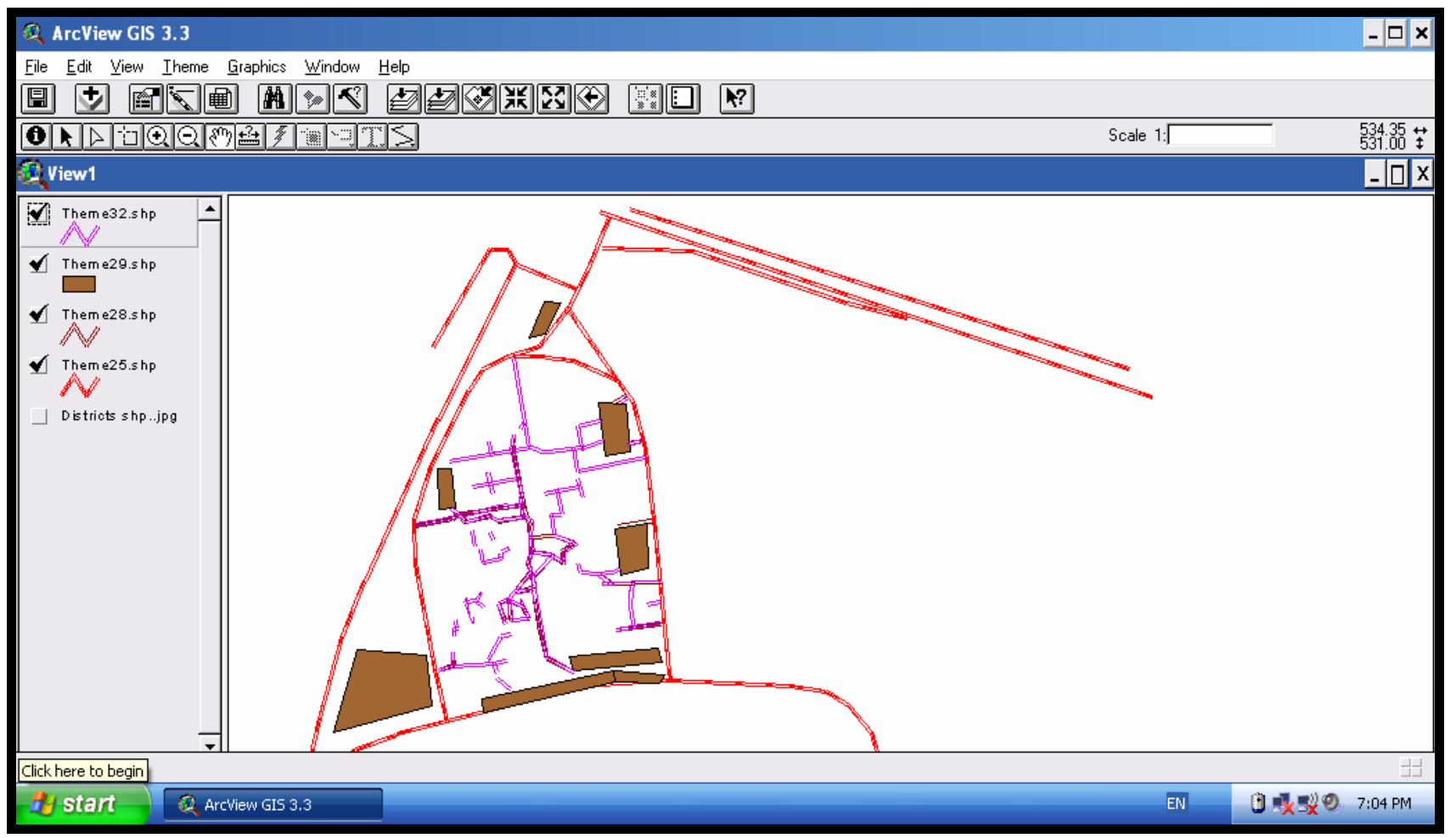

Figure 12. All the themes use.

Table 3. The details of each section of the road ways of Nahrain University.

\begin{tabular}{|c|c|c|c|c|c|}
\hline \multicolumn{2}{|c|}{ Sections Types of Pavements } & \multirow[t]{2}{*}{ Types of Distresses } & \multirow{2}{*}{$\begin{array}{c}\begin{array}{c}\text { Degree of } \\
\text { Distresses }\end{array} \\
\text { Moderate }\end{array}$} & \multirow{2}{*}{$\begin{array}{c}\begin{array}{c}\text { Present Serviceability } \\
\text { Index (PSI) }\end{array} \\
2\end{array}$} & \multirow{2}{*}{$\begin{array}{c}\begin{array}{c}\text { Pavement Maintenance } \\
\text { Treatments }\end{array} \\
2,7\end{array}$} \\
\hline 1 & Rigid Pavement & & & & \\
\hline 2 & Flexible Pavement & Transverse Cracking & High & 1 & $2,6,13$ \\
\hline 3 & Flexible Pavement & Transverse Cracking & High & 1 & $2,6,13$ \\
\hline 4 & Flexible Pavement & Transverse Cracking & Low & 4 & 2 \\
\hline 5 & Flexible Pavement & Longitudinal Cracking & Low & 3 & $2,6,1$ \\
\hline 6 & Flexible Pavement & Raveling/Weathering & High & 1 & $6,12,11$ \\
\hline 7 & Flexible Pavement & Rutting & Moderate & 2 & $6+8$ \\
\hline 8 & Flexible Pavement & Alligator Cracking & Moderate & 2 & $6,3,11,4$ \\
\hline 9 & Flexible Pavement & Transverse and Longitudinal Cracking & Low & 3 & $2+6,1$ \\
\hline 10 & Flexible Pavement & Random/Block Cracking & Moderate & 2 & 2,6 \\
\hline 11 & Flexible Pavement & Transverse Cracking & Moderate & 2 & 2,6 \\
\hline 12 & Flexible Pavement & Random/Block Cracking & High & 1 & $12,6,14$ \\
\hline 13 & Flexible Pavement & Random/Block Cracking & High & 1 & $6,12,14$ \\
\hline 14 & Flexible Pavement & Random/Block Cracking & High & 1 & $12,6,14$ \\
\hline 15 & Flexible Pavement & Random/Block Cracking & High & 1 & $12,6,14$ \\
\hline 16 & Rigid Pavement & Joint Distress & High & 1 & 3,4 \\
\hline 17 & Flexible Pavement & Alligator Cracking & High & 1 & 15,13 \\
\hline 18 & Flexible Pavement & Random/Block and Rutting & Moderate & 2 & $2+6+8$ \\
\hline 19 & Flexible Pavement & Transverse + Longitudinal + Alligator Cracking & High & 1 & $2,6,13+15$ \\
\hline 20 & Rigid Pavement & Slab Cracking & Low & 3 & 2,4 \\
\hline 21 & Rigid Pavement & Slab Cracking & High & 1 & 3,9 \\
\hline 22 & Flexible Pavement & Transverse Cracking & Low & 4 & 2,1 \\
\hline 23 & Flexible Pavement & Transverse Cracking & Low & 4 & 2 \\
\hline
\end{tabular}




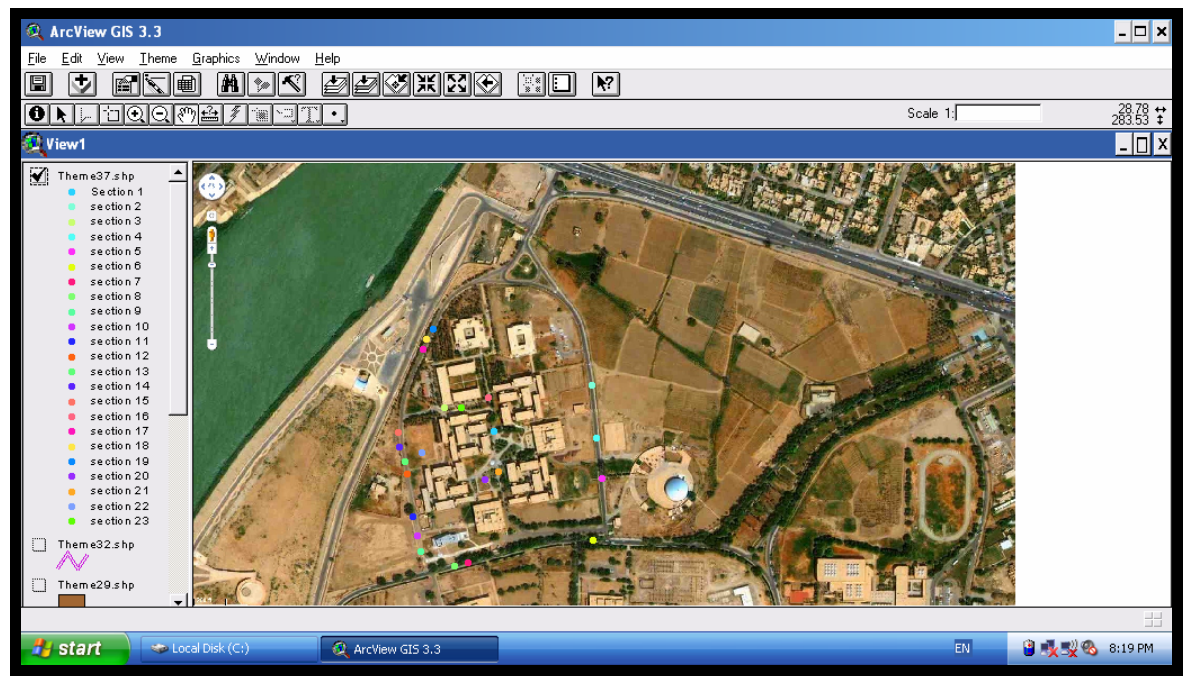

Figure 13. The selected sections.

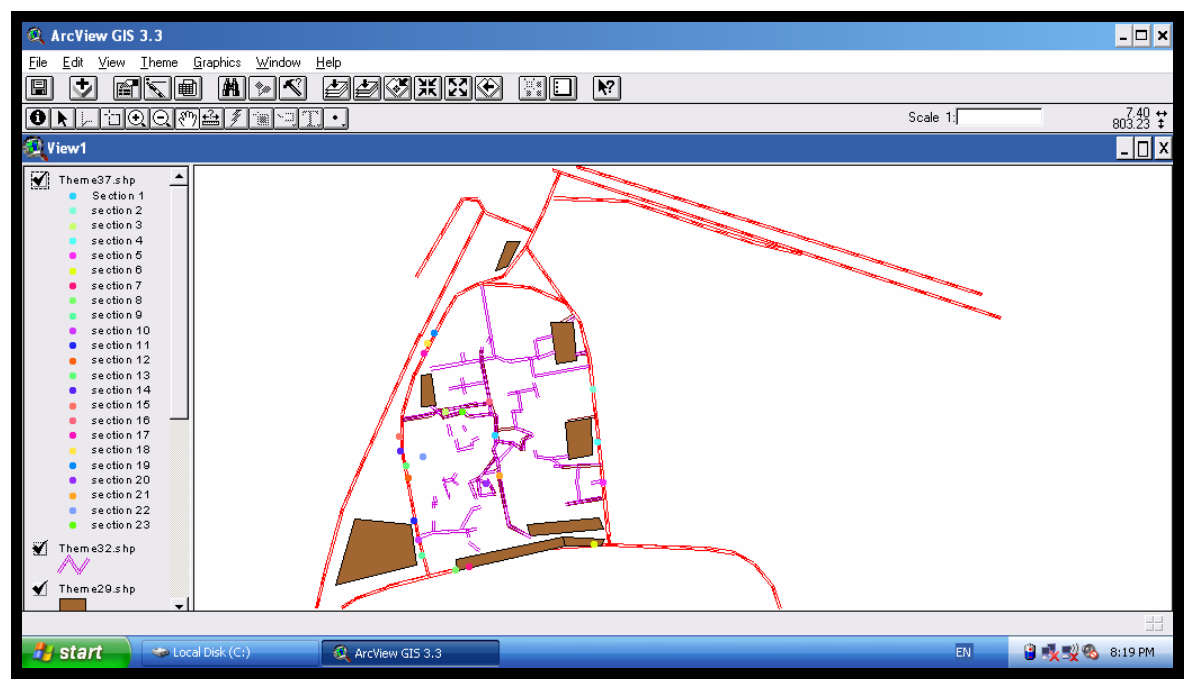

Figure 14. The selected sections.

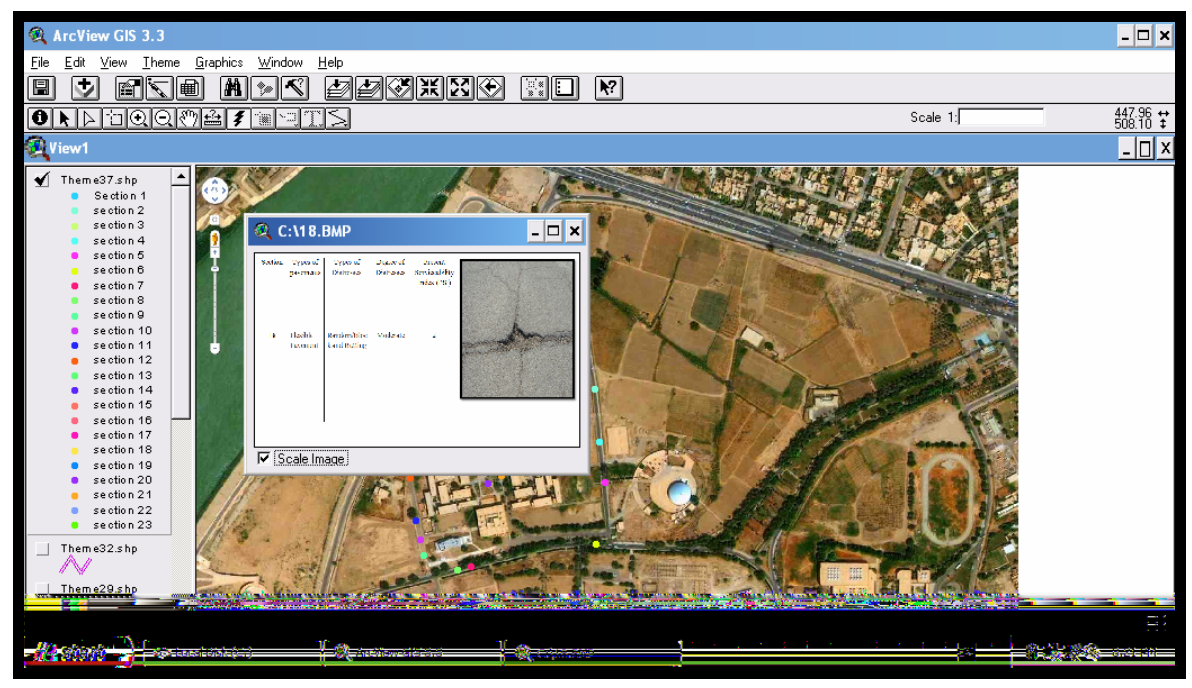

Figure 15. The inspection data of Section 1. 


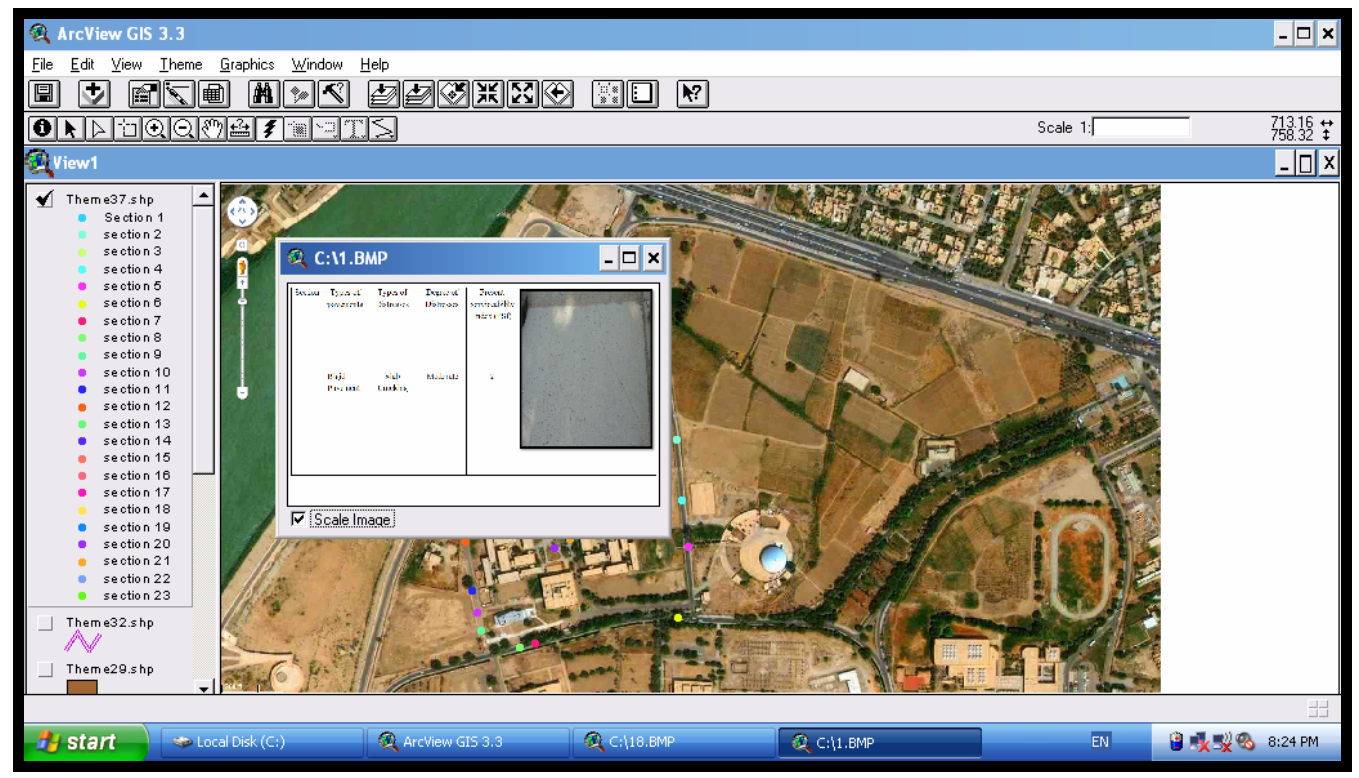

Figure 16. The inspection data of Section 18.

\& maintenance history and so on.

6) There is a great need of long-term commitment of officials, pavement managers, public and road users towards the conservation and protection of the university pavement assets.

\section{REFERENCES}

[1] H. M. Ahmed, "GIS, a Tool for Pavement Management," Royal Institute of Technology (KTH), Stockholm, 2009.

[2] Highway Research Board, "Present Serviceability Index," AASHO Road Test PSR, 1962.

http://www.nebraskatransportation.org/docs/pavement.pd f

[3] J. Chang, C. Hung and J. Lin, "Application of Advanced Computation on Flexible Pavement Maintenance Management System in Taiwan," National Central University, Taoyuan, 2005.

[4] M. Johanns and J. Craig, "Pavement Maintenance Manual," NDOR, Naraska, 2002.
[5] D. Gary, "Pavement Management Applications Using Geographic Information Systems," Transportation Research Board, 2004.

http://www.national-academies.org/trb/bookstore

[6] S. Jendia and M. Al Hallaq, "Development of a Pavement Maintenance Management System (PMMS) for Gaza City," The Islamic University of Gaza, Palestine, 2005.

[7] H. A. Elhadi, "GIS, a Tool for Pavement Management," Master's of Science Thesis in Geoinformatics, Royal Institute of Technology (KTH), Stockholm, 2009.

[8] Farallon Geographic Inc., "GIS PavePlan Application Helps San Mateo County Manage Pavement Conditions," 2005.

http://www.fargeo.com/press/releases/gis-paveplan-applic ation-helps-san-mateo-county-managepavement- conditions.htm

[9] J. Neelam and P. K. Nanda, "Geographical Information System for Pavement Management Systems," Map Asia Conference, India, 2003. 